\title{
Pengaruh Budaya Organisasi terhadap Kinerja Karyawan Bagian Penjualan pada PT. Agung Automall Paal 10 Jambi
}

\author{
Muhammad Emil ${ }^{1 *}$, Suci Permata Sari \\ ${ }^{1}$ Dosen Fakultas Ekonomi Universitas Batanghari Jambi \\ "Correspondence email: muhammademi174@gmail.com, ${ }^{2}$ sucipermatasari549@gmail.com
}

\begin{abstract}
The population of this research is the organizational culture and employee performance of the sales department at PT. Agung Automall Paal 10 Jambi in 2019 an many as 53 people. Using a census that is all the population made responden. Based on the results of simple linear regression analysis, showing the equation $Y=0.844+0.682 X+e$. With a correlation of $44 \%$ or 0,440. The value of determination is 0,194 or 19,4\%. Where it is intended that the influence of work culture on performance is $19,4 \%$ while $80,6 \%$ is influenced by other variables not examined in this study. T test value of 3.503 with a significance value of $0.00<0.05$ which is greater than the value of t table of 2.00758.
\end{abstract}

Keywords: Organizational Culture, Performance.

\section{Pendahuluan}

Organisasi dengan budaya yang kuat akan mempengaruhi perilaku dan efektifitas kinerja karyawan. Kinerja karyawan akan berjalan sesuai dengan budaya yang dianutnya dalam organisasi tersebut. Selain itu, penerapan budaya dalam suatu perusahaan juga akan membentuk karakter karyawan dengan sendirinya dalam menjalankan tugasnya dan mencapai tujuan dari perusahaan. Menciptakan keakraban pada anggota organisasi juga menjadi salah satu faktor pendukung keberhasilan kinerja yang baik. Keakraban tersebut tumbuh dari adanya rasa nyaman pada individu ataupun kelompok pada anggota organisasi. Maka perusahaan perlu menciptakan susasana keakraban guna mendukung keberhasilan perusahaan secara psikologis. Penilaian kinerja dilakukan tidak semata demi kepentingan perusahaan karena penilaian kinerja perlu dilakukan demi perkembangan kualitas dari karyawan di setiap devisi pekerjaan. Penilaian kinerja karyawan juga dilakukan dengan tujuan mengukur seberapa jauh posisi kinerja yang diberikan dari standar yang diharapkan oleh perusahaan. Hal ini jelas penting, karena jika karyawan tidak dapat memenuhi standar kinerja yang diberikan maka perusahaan tidak akan mencapai target yang telah ditetapkan. Lambat laun perusahaan akan menurun produktivitasnya dan tidak dapat berkembang. Jika penilaian kinerja tidak dilakukan, bisa jadi perusahaan tidak akan memiliki informasi di mana posisi kinerja yang diberikan karyawan dengan target yang diharapkan perusahaan. Keterlambatan identifikasi pada poin ini berakibat fatal tidak hanya bagi karyawan yang dimiliki namun juga untuk perusahaan secara keseluruhan. Dengan melakukan penilaian kinerja, perusahaan juga telah memberikan fasilitas kepada setiap karyawannya untuk lebih mengetahui tanggung jawab apa yang dimiliki, target apa yang telah tercapai, dan apa yang harus dilakukan untuk meraih target yang masih belum tercapai.

Demi tercapainya tujuan yang telah ditetapkan instansi akan dapat meningkatkan kinerja karyawan dengan cara mewujudkan budaya organisasi yang sesuai dengan harapan karyawan. Setiap individu selalu mempunyai sifat yang berbeda satu dengan yang lainnya. Sifat tersebut dapat menjadi ciri khas bagi seseorang sehingga kita dapat mengetahui bagaimana sifatnya. Sama halnya dengan manusia, organisasi juga mempunyai sifat-sifat tertentu. Melalui sifat-sifat tersebut kita juga dapat mengetahui bagaimana karakter dari organisasi tersebut. Sifat tersebut kita kenal dengan budaya organisasi atau organization culture. Budaya-budaya yang dimiliki oleh setiap suku bangsa memiliki sistem nilai dan norma dalam mengatur masing-masing anggotanya dari suku bangsa tersebut maupun orang yang berasal dari suku lain, dengan demikian dapat dikatakan bahwa suatu organisasi juga memiliki budaya yang mengatur bagaimana anggota-anggotanya untuk bertindak. Kekuatan-kekuatan dalam lingkungan eksternal organisasi dapat mengisyaratkan kebutuhan perubahan budaya, misalnya dengan adanya persaingan yang makin tajam dalam suatu lingkungan instansi menuntut perubahan budaya organisasi untuk senantiasa mampu merespon keinginan masyarakat dengan lebih cepat. Di samping berasal dari lingkungan eksternal, kekuatan perubahan budaya juga bisa berasal dari dalam/internal, sebagai contoh jika kepala kantor menerapkan pendekatanpendekatan baru untuk manajemen organisasi agar tercipta kinerja yang baik.

Tujuan penelitian untuk menganalisis pengaruh budaya organisasi terhadap kinerja karyawan pada PT. Agung Automall Paal 10 Jambi. 


\section{Landasan Teori}

\section{Budaya Organisasi}

Mas'ud (2004) Budaya organisasi adalah sistem makna, nilai-nilai dan kepercayaan yang dianut bersama dalam suatu organisasi yang menjadi rujukan untuk bertindak dan membedakan organisasi satu dengan organisasi lain. Budaya organisasi selanjutnya menjadi identitas atau karakter utama organisasi yang dipelihara dan dipertahankan (Mas'ud, 2004). Suatu budaya yang kuat merupakan perangkat yang sangat bermanfaat untuk mengarahkan perilaku, karena membantu karyawan untuk melakukan pekerjaan yang lebih baik sehingga setiap karyawan pada awal karirnya perlu memahami budaya dan bagaimana budaya tersebut terimplementasikan. Lebih lanjut dikatakan bahwa di dalam pertumbuhan perusahaan dan produk knowledge-based yang memuaskan, pengendalian dan pemahaman budaya perusahaan suatu organisasi merupakan kunci tanggung jawab pimpinan, seperti halnya sebagai suatu alat yang vital bagi manajemen jika ingin mencapai kinerja yang tinggi dan menjaga nilai pemegang saham.

\section{Kinerja Karyawan}

Menurut Pandi (2018) kinerja adalah kesedian seseorang atau kelompok orang untuk melakukan kegiatan atau menyempurnakan sesuai dengan tanggung jawabnya dengan hasil seperti yang diharapkan. Menurut Moeherioni (2012:95) yaitu kinerja atau performance merupakan gambaran mengenai tingkat pencapaian pelaksanaan suatu program kegiatan atau kebijakan dalam mewujudkan sasaran, tujuan, visi, dan misi organisasi yang dituangkan melalui perencanaan strategis suatu organisasi.

\section{Hubungan Variabel Budaya Organisasi Terhadap Kinerja Karyawan}

Robbins (2006:748) mendeskripsikan bagaimana nilai-nilai/karakteristik dari budaya organisasi terhadap kinerja. Robbins mendeskripsikan budaya organisasi sebagai suatu variabel. Anggota-anggota organisasi membentuk suatu persepsi subjektif secara keseluruhan mengenai organisasi berdasarkan kepada faktor-faktor seperti toleransi resiko, tekanan pada tim, dukungan orang, dan sebagainya. Persepsi yang yang terbentuk itu sebenarnya merupakan budaya atau kepribadian dari organisasi yang bersangkutan. Dukungan atau penolakan sebagaimana bentukan persepsinya, mempengaruhi anggota-anggota organisasi, atau dampak yang lebih besar adalah kepada terbentuknya budaya yang lebih kuat. Kinerja yang tinggi dihubungkan dengan budaya yang kuat. Sebaliknya, budaya yang lemah dihubungkan dengan kinerja yang rendah pula. Dengan budaya organisasi yang kuat dan kokoh diharapkan dapat mempererat individu yang ada didalam organisasi sehingga dapat membentuk sikap dan perilaku yang dapat menghasilkan kinerja yang maksimal demi peningkatan kinerja institusi/organisasi melalui pemahaman Budaya Organisasi.

\section{Metode}

Menurut Sugiono (2017) populasi merupakan wilayah generalisasi yang terdiri dari atas: obyek/subyek yang mempunyai kualitas dan karakteristik tertentu yang ditetapkan oleh peneliti untuk dipelajari dan kemudian ditarik kesimpulannya. Populasi pada penelitian ini berjumlah 53 orang Sales Counsultant pada PT. Agung Automall Paal 10 Jambi. Dengan menggunakan metode sensus yaitu populasi dijadikan sampel informasi.

\section{Alat Analisis}

Regresi linier sederhana dipengaruhi oleh dua Variabel. Persamaan regresi tersebut adalah sebagai berikut: $\mathrm{Y}=\mathrm{a}+\mathrm{bX}+\mathrm{e}$

Keterangan: $\mathrm{Y}=$ Kinerja; $\mathrm{X}=$ Budaya Organisasi; $\mathrm{b}=$ Koefisien Regresi; $\mathrm{a}=$ Konstanta; $\mathrm{e}=$ Error

\section{Uji F (Uji Simultan)}

1. Jika F Hitung > F Tabel ( F Hitung lebih besar dari F tabel) maka terdapat pengaruh antar variable $X$ terhadap Variabel Y.

2. Jika Nilai Sig (signifikansi) $<0,05$ ( Nilai Signifikansi kecil dari 0,05) maka terdapat pengaruh antar variable $\mathrm{X}$ terhadap Variabel Y.

\section{Uji T (Uji Parsial)}

Pengujian ini dilakukan untuk mengetahui tingkat signifikan pengaruh masing-masing variabel independen terhadap variabel dependen dengan menguji koefesien variabel tersebut. Untuk melakukan pengujian $\mathrm{T}$ dan dasar pengambilan keputusan sebagai berikut:

1. Jika $\mathrm{t}$ hitung $>\mathrm{t}$ table ( $\mathrm{t}$ hitung lebih besar dari $\mathrm{t}$ tabel) maka terdapat pengaruh antar variable $\mathrm{X}$ terhadap Variabel Y.

2. Jika Nilai Sig (signifikansi) < 0,05 ( Nilai Signifikansi kecil dari 0,05) maka terdapat pengaruh antar variable $\mathrm{X}$ terhadap Variabel Y. 
Muhammad Emil dan Suci Permata Sari, Pengaruh Budaya Organisasi Terhadap Kinerja Karyawan Bagian Penjualan pada PT. Agung Automall Paal 10 Jambi

\section{Koefisien Determinasi}

Pada hakikatnya nilai $\mathrm{R}$ berkisar antara -1 dan 1 , bila $\mathrm{r}$ mendekati -1 atau 1 maka dapat dikatakan bahwa ada hubungan yang erat antara variabel bebas dengan variabel terikat. Bila $\mathrm{R}$ mendekati 0 , maka dapat dikatakan bahwa hubungan antara variabel bebas dengan variabel terikat sangat lemah atau bahkan tidak ada.

\section{Hasil}

Tabel 1

Koefisien

\begin{tabular}{|c|c|c|c|c|}
\hline \multirow[b]{2}{*}{ Model } & Unstandardized Coefficients & \multirow[t]{2}{*}{ Standardized Coefficients } & \multirow[b]{2}{*}{$\mathrm{t}$} & \multirow[b]{2}{*}{ Sig. } \\
\hline & $\begin{array}{cc}\text { B } & \text { Std. Error } \\
\end{array}$ & & & \\
\hline $1 \quad$ (Constant) & $.844 \quad 1.531$ & .132 & 1.531 & .132 \\
\hline Budaya_Organisasi & .6823 .503 & .001 & 3.503 & .001 \\
\hline
\end{tabular}

Sumber : data olahan

Berdasarkan hasil analisis regresi linier sederhana pada tabel di atas dapat diperoleh model persamaan regresi yang diperoleh adalah: $\mathrm{Y}=0.844+0.682 \mathrm{X}+\mathrm{e}$

Model regresi tersebut dapat dijelaskan :

1. Nilai konstanta sebesar 0.844 artinya apabila variabel independen yaitu Budaya Organisasi $(\mathrm{X})$ bernilai nol (0), maka variabel dependen (Y) yaitu Kinerja akan bernilai tetap sebesar 0.844 .

2. Koefisien regresi variabel Budaya Organisasi (X) bernilai positif sebesar 0.682 artinya apabila variable X Budaya Organisasi mengalami peningkatan sebesar 1 (satu) satuan sedangkan variabel lainnya dianggap konstan, maka variabel Y yaitu Harga Saham akan mengalami peningkatan sebesar 0.682. (kalau positif, Variabel X Meningkat dan Variabel Y meningkat).

\section{Uji Hipotesis}

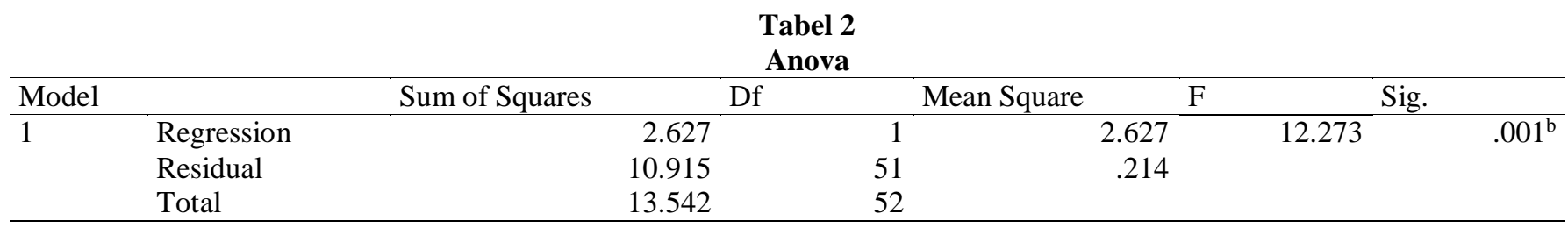

Sumber : data olahan

Dengan membandingkan fhitung dengan ftabel dengan taraf signifikan $\alpha=0.05$. Dapat diketahui bahwa fhitung sebesar 12.273 dengan membandingkan ftabel $\alpha=0,05$ dengan derajat bebas pembilang (banyaknya X) $=1$ dan derajat penyebutnya $(\mathrm{N}-\mathrm{K}-1)=4.03$, didapat $\mathrm{f}$ tabel sebesar 4.03. F hitung lebih besar dari $\mathrm{f}$ tabel $(12.273>4.03)$ maka Ho ditolak dan Ha diterima, berarti ada pengaruh yang signifikan antara variabel independen (x) secara bersama-sama terhadap variabel dependen (y). Yang artinya dapat dikatakan bahwa secara simultan variabel independen Budaya Organisasi berpengaruh terhadap variabel dependen Kinerja.

Berdasarkan hasil uji $t$ (parsial) pada model regresi, hasil perbandingan antara $t_{\text {hitung }}$ dan $t_{\text {tabel }}$ yang menunjukan $t_{\text {hitung }}$ sebesar (3.503) sedangkan $t_{\text {tabel }}$ sebesar 2.00758. Dari hasil tersebut terlihat bahwa $t_{\text {hitung }}>t_{\text {tabel }}$ yaitu (3.503) $>$ 2.00758 maka dapat disimpulkan bahwa $\mathrm{H}_{\mathrm{o}}$ ditolak $\mathrm{H}_{\mathrm{a}}$ diterima artinya secara parsial variabel Budaya Organisasi berpengaruh positif terhadap Kinerja.

Koefisien Determinasi $\left(\mathbf{R}^{2}\right)$

Tabel 3

Summary

\begin{tabular}{crrrrr}
\hline Model & R & R Square & Adjusted R Square & Std. Error of the Estimate & Durbin-Watson \\
\hline 1 & $.440^{\mathrm{a}}$ & .194 & .178 & .46262 & 1.941 \\
\hline
\end{tabular}

Sumber : data olahan

Berdasarkan hasil pengujian koefisien determinasi pada tabel diatas, menunjukkan bahwa nilai R Square sebesar 0.194 yang artinya bahwa besarnya kontribusi variabel independen yaitu X Budaya Organisasi, mempengaruhi variable Y Kinerja sebesar $(0,194 \times 100=19.4 \%)$, sedangkan sisanya $(100 \%-19.4 \%=80.6 \%)$ dipengaruhi oleh variabel-variabel lain di luar penelitian ini. 
Secara Simultan Budaya Organisasi berpengaruh secara signifikan terhadap Kinerja Karyawan. Hal ini di tunjukan dengan $f_{\text {hitung }}>f_{\text {tabel }}(12.273>4.03)$ maka Ho ditolak dan Ha diterima, berarti ada pengaruh yang signifikan antara variabel independen (x) secara bersama-sama terhadap variabel dependen (y). Yang artinya dapat dikatakan bahwa secara simultan variabel independen Budaya Organisasi berpengaruh terhadap variabel dependen Kinerja. Berdasarkan hasil uji t (parsial) pada model regresi, hasil perbandingan antara $t_{\text {hitung }}$ dan $t_{\text {tabel }}$ yang menunjukan $t_{\text {hitung }}$ sebesar (3.503) sedangkan $t_{\text {tabel }}$ sebesar (2.00758). Dari hasil tersebut terlihat bahwa $t_{\text {hitung }}>t_{\text {tabel }}$ yaitu $3.503>$ 2.00758 maka dapat disimpulkan bahwa Ho ditolak dan Ha diterima artinya secara parsial variabel Budaya Organisasi berpengaruh positif terhadap Kinerja.

\section{Simpulan}

Berdasarkan hasil pembahasan yang dilakukan pada bab sebelumnya maka dirumuskan beberapa kesimpulan sebagai berikut:

1. Berdasarkan hasil uji $\mathrm{F}$ secara simultan diketahui bahwa secara bersama-sama berpengaruh secara signifikan, dapat dilihat dari dengan $\mathrm{f}_{\text {hitung }}>\mathrm{f}_{\text {tabel }}(12.273>4.03)$ maka Ho ditolak dan Ha diterima, berarti ada pengaruh yang signifikan antara variabel independen (x) secara bersama-sama terhadap variabel dependen (y). Yang artinya dapat dikatakan bahwa secara simultan variabel independen Budaya Organisasi berpengaruh terhadap variabel dependen Kinerja.

2. Berdasarkan hasil uji T secara parsial variabel Budaya Organisasi berpengaruh positif terhadap Kinerja. Dapat dilihat dari hasil perbandingan antara $t_{\text {hitung }}$ dan $t_{\text {tabel }}$ yang menunjukan $t_{\text {hitung }}$ sebesar (3.503) sedangkan $t_{\text {tabel }}$ sebesar 2.00758. Dari hasil tersebut terlihat bahwa $t_{\text {hitung }}>t_{\text {tabel }}$ yaitu $3.503>2.00758$ maka dapat disimpulkan bahwa Ho ditolak Ha diterima.

\section{Daftar Pustaka}

Afandi, Pandi. 2018. Manajemen Sumberdaya Manusia Teori Konsep dan Indikator. Pekanbaru: Zanafa Publishing.

Asnawi, Tetty. 2011 Kepemimpinan, Hamada Prima. Jambi

Hasibuan, H. Malayu S.P. 2009. Manajemen Sumber Daya Manusia. Yogyakarta : BPFE-UGM.

Hasibuan, H. Malayu S.P. 2016. Manajemen Sumber Daya Manusia. Edisi. Revisi. Bumi Aksara, Jakarta

Mas'ud, 2004, Survey Diagnosis Organizational Undip Semarang.

McShane, Stephen L and Mary Ann Von Glinow, 2005. Organizional Behavior Boston: McGraw-Iiill

Moeheriono, 2012, Kinerja Karyawan, Kencana Prenada Media Group, Jakarta

Robbins, S. P. and Mary Coulter. (2006:748). Management, Ninth Edition. International Edition. New Jersey : Pearson Education. Inc.

Sedarmayanti 2007. Sumber Daya Manusia dan Produktivitas Kerja. CV. Mandar Maju, Bandung.

Sutrisno Edy. 2010. Budaya Organisasi. Kencana Prenada Media Group.

Syekh, Sayid. 2011. Pengantar Statistik Ekonomi dan Sosial. Gunung Persada Perss, Jakarta.

Sujarweni, Wiratna, 2015. SPSS untuk Penelitian. Pustaka Baru, Yogyakarta

Umar, H., 2013. Desain Penelitian MSDM dan perilaku karyawan. Rajawali Pers, Jakarta 